\title{
Activation of the Promoter of the Tnt1 Retrotransposon in Tomato After Inoculation with the Fungal Pathogen Cladosporium fulvum
}

\author{
Corinne Mhiri, ${ }^{1}$ Pierre J. G. M. De Wit, ${ }^{2}$ and Marie-Angèle Grandbastien ${ }^{1}$ \\ ${ }^{1}$ Laboratoire de Biologie Cellulaire, INRA, Route de St Cyr, 78026 Versailles Cedex, France; ${ }^{2}$ Agricultural \\ University Wageningen, Department of Phytopathology, Binnenhaven 9, 6709 PD Wageningen, \\ The Netherlands \\ Accepted 24 March 1999.
}

\begin{abstract}
The copia-like Tnt1 element of tobacco is one of the few active plant retrotransposons and is transcriptionally activated, in tobacco and in heterologous species, by biotic and abiotic stress factors. In order to establish more precisely the link between Tnt1 activation and plant defense responses, the expression of the Tnt1 promoter was studied in a gene-for-gene pathosystem, the interaction between tomato and the fungal pathogen Cladosporium fulvum. In compatible interactions, Tnt1 expression is highly induced throughout the leaf regions colonized by the fungus, while in incompatible interactions Tnt1 induction is transient and localized in distinct foci. Tnt1 expression after fungal inoculation parallels the differential activation of tomato defense genes. Tnt1 expression is induced by nonspecific factors of plant or fungal origin present in apoplastic fluids of leaf tissues infected by virulent races of C. fulvum, but is also activated by specific factors resulting from the interaction between fungal avirulence peptides and plant resistance genes. Tnt1 activation by apoplastic fluids containing avirulence peptides of $C$. fulvum is detected soon after elicitation. These results demonstrate that Tnt1 transcriptional activation correlates with biological responses of tomato to infection by $C$. fulvum and is mediated through signals originating from both racespecific and non-race-specific perception pathways.
\end{abstract}

Additional keywords: Lycopersicon esculentum, pathogen attack, transposable element.

Plants respond to pathogen attack by coordinated induction of an array of defense response genes such as pathogenesisrelated (PR) protein genes and genes encoding core enzymes involved in phenylpropanoid metabolism (Bol et al. 1990; Bowles 1990; Dixon and Lamb 1990), which are involved either in the production of compounds aimed to restrict pathogen development or in triggering signal transduction pathways (Hammond-Kosack and Jones 1996). Some of the defense response genes are also expressed in healthy plant tissues, in

Corresponding author: Marie-Angèle Grandbastien; Laboratoire de Biologie Cellulaire, INRA - Centre de Versailles, F-78026 Versailles Cedex, France; Telephone: 33 (1) 308330 24; Fax: 33 (1) 308330 99; E-mail: gbastien@versailles.inra.fr response to developmental signals. Defense genes can also be induced by a range of abiotic elicitors (Bailey 1982; Kessmann et al. 1994), by nonpathogenic microbes (Jakobek and Lindgren 1993), or during successful pathogen infections, indicating that the activation of defense genes is part of a general response to stress conditions. Although plant defense responses appear to be complex, the activation of many genes, induced by specific and nonspecific signal transduction systems under different environmental circumstances, is highly coordinated (Dixon and Lamb 1990).

A growing body of evidence shows that stress also appears to be a major factor in the activation of particular types of genomic sequences, defined as "transposable elements." They represent mobile genetic entities able to insert at different positions in the genome, and to alter the function or the regulation of genes in which or next to which they insert (Finnegan 1992). Their biological impact is still poorly understood, but they constitute a major fraction of the eukaryotic genome and might play an important role in generating genetic variability. Transposition is not a random process, as it is controlled by the element itself and by signals of host origin. It is also under the control of external factors such as environmental changes or stress. DNA-damaging irradiation, chemical agents, or in vitro tissue culture, for instance, are known to stimulate the expression or the mobilization of transposable elements, in both animal and plant systems (Strand and McDonald 1985; Bradshaw and McEntee 1989; Fedoroff 1989; Hirochika 1993; Grandbastien 1998). Other external factors, such as infections by pathogens, might also mobilize transposable elements. Transposition of several maize elements has been reported after infection by barley stripe mosaic virus (BSMV) (Dellaporta et al. 1984; Johns et al. 1985).

We have shown that the transcription of the tobacco Tnt1 retrotransposon (Grandbastien et al. 1989) is activated by various biotic and abiotic factors, which are also able to elicit plant defense responses. Tnt 1 belongs to the class of retrotransposons, closely related to retroviruses and transposes via the formation of a daughter copy by reverse transcription of an RNA intermediate (Boeke and Corces 1989). Tnt1 expression is developmentally regulated, and is low in most tobacco tissues, except roots. Tnt1 transcription in tobacco is strongly induced by several factors of microbial origin, such as fungal extracts and elicitins or supernatants of phytopathogenic bac- 
teria (Pouteau et al. 1991, 1994). The activation of the expression of the Tnt1 promoter by microbial factors is conserved in heterologous species such as tomato and Arabidopsis thaliana (Moreau-Mhiri et al. 1996) and is induced, both in tobacco and heterologous species, by wounding and abiotic factors such as salicylic acid and $\mathrm{CuCl}_{2}$ (Mhiri et al. 1997; Vernhettes et al. 1997). Tnt1 expression is also induced by virulent pathogens such as the bacterium Pseudomonas syringae on $A$. thaliana or cucumber mosaic virus (CMV) on tomato (Moreau-Mhiri et al. 1996). These results strongly suggest a link between Tnt 1 transcriptional activation and plant defense responses. Little is known, however, about the mechanisms and triggers involved in Tnt 1 stress activation. Tnt 1 expression is linked to the necrosis-inducing ability of fungal elicitins (Pouteau et al. 1994), and remains localized around $\mathrm{CuCl}_{2}$-induced necrotic lesions or at injury points resulting from mechanical wounding (Mhiri et al. 1997). Furthermore, Tnt 1 activation by CMV infection in tomato is enhanced by co-inoculation with a satellite RNA that induces a generalized necrosis of the plant (Moreau-Mhiri et al. 1996), and is detected after inoculation of tobacco mosaic virus (TMV) on tobacco carrying the $N$ resistance gene, which is associated with the hypersensitive response (HR) (Grandbastien et al. 1997). However, triggering of the Tnt1 promoter in necrotic tissues does not require cellular death per se and precedes necrotic symptoms in most cases, suggesting that earlier events are involved in Tnt1 transcriptional activation. Interestingly, Tnt1 expression appears associated with the accumulation of colored phenolic compounds in CMV-infected tomato plants (Grandbastien et al. 1997).

In order to elucidate the possible link between Tnt 1 expression and the induction of plant defense responses, we decided to study Tnt 1 expression in a pathosystem that has a gene-forgene basis. In such a system, the outcome of the infection is determined by specific genetic interactions between the plant and the pathogen (Keen 1990), leading either to successful host colonization (compatible interaction) or to pathogen restriction associated with an HR (incompatible interaction). In most systems, the patterns of expression of plant defense genes are known to differ between the two types of interactions. A gene-for-gene interaction thus allows the detailed study, inside the same pathosystem, of Tnt1 transcriptional activation under various conditions of physiological stress, such as stress imposed by a virulent strain of a pathogen or such as HR imposed by an avirulent strain of the same pathogen. A gene-for-gene interaction also allows a direct comparison of Tnt 1 activation patterns with the differential activation patterns of plant defense genes.

Several gene-for-gene systems are available for the plant species in which stress activation of the Tnt1 promoter was evidenced. We chose the interaction between tomato and the biotrophic fungal pathogen Cladosporium fulvum (De Wit 1995), because this interaction is well characterized and represents the most versatile one, in terms of the richness of available gene-for-gene combinations and in terms of experimental possibilities. The interaction between tomato and C. fulvum is characterized by semidominant plant resistance genes (termed $C f$ ) and complementary fungal avirulence genes (termed Avr) encoding race-specific proteinaceous elicitors (De Wit and Spikman 1982). Resistance to this fungus is observed when the plant resistance gene matches the fungal avirulence gene, while in all other gene combinations the fungus is able to develop a successful infection. Several fungal avirulence genes (De Wit 1995) and tomato resistance genes (HammondKosack and Jones 1997) have been isolated. The defense responses in tomato after inoculation with C. fulvum have also been studied in detail, both at the level of differential gene expression (Van Kan et al. 1992; Danhash et al. 1993; Ashfield et al. 1994; Wubben et al. 1996) and protein accumulation (Joosten et al. 1995 and references therein). Furthermore, biological assays for the tomato- $C$. fulvum interaction have been developed with race-specific fungal elicitors present in apoplastic fluids (AFs) of C. fulvum-infected leaves. When injected into leaves of tomato genotypes carrying the complementary resistance gene, these AFs induce an HR (De Wit and Spikman 1982), and $C f$-dependent physiological and molecular changes can be induced and monitored in the absence of the fungus (Vera-Estrella et al. 1992; Ashfield et al. 1994; Hammond-Kosack et al. 1996; May et al. 1996; Wubben et al. 1996). Furthermore, some C. fulvum avirulence genes have been expressed in transgenic plants (Hammond-Kosack et al. 1994; Honée et al. 1995), offering the possibility to test easily for specific responses to an avirulence peptide in the absence of other components present in AFs of C. fulvum-infected leaves.

The tomato- $C$. fulvum system thus allows study of Tnt1 expression both after infections by virulent and avirulent fungal races, and after elicitor treatments with plant and fungal components to mimic various gene-for-gene combinations. In this way, Tnt1 expression can be compared with the expression of tomato defense genes under similar conditions. Our studies were performed with transgenic tomato lines carrying the long terminal repeat- $\beta$-glucuronidase (LTR-GUS) translational fusion (Pouteau et al. 1991), which consists of the GUS reporter gene (Jefferson et al. 1987) placed under control of the $5^{\prime}$ LTR of Tnt1-94, an active member of the Tnt1A subfamily. Previous results have shown that the expression of the LTR-GUS construct parallels Tnt1 transcription (Pouteau et al. 1991; Lucas et al. 1995; Moreau-Mhiri et al. 1996) and that the Tnt194 LTR contains regulatory sequences involved in Tnt1 expression (Casacuberta and Grandbastien 1993; Vernhettes et al. 1997). Different $C f$ resistance genes, originating from nearisogenic lines (NILs; Tigchelaar 1984), were introduced by crossing these lines with LTR-GUS transgenic lines, in order to study the expression of the Tnt1 promoter in genetic backgrounds differing only in one $C f$ resistance gene. This enabled us to study the expression of the Tnt 1 promoter, by monitoring either the GUS activity or the steady-state transcript levels of the LTR-GUS construct, after inoculation with several fungal races or after treatment with AFs containing race-specific elicitors, produced by some of these races, and to compare Tnt1 expression with the expression of several tomato defense genes.

\section{RESULTS}

\section{Patterns of LTR-GUS activity after inoculation with $C$. fulvum.}

The kinetics and spatial localization of the expression of the LTR-GUS construct after inoculation of tomato with $C$. fulvum was first studied by histochemical GUS staining of leaf samples. We compared LTR-GUS activity between an 


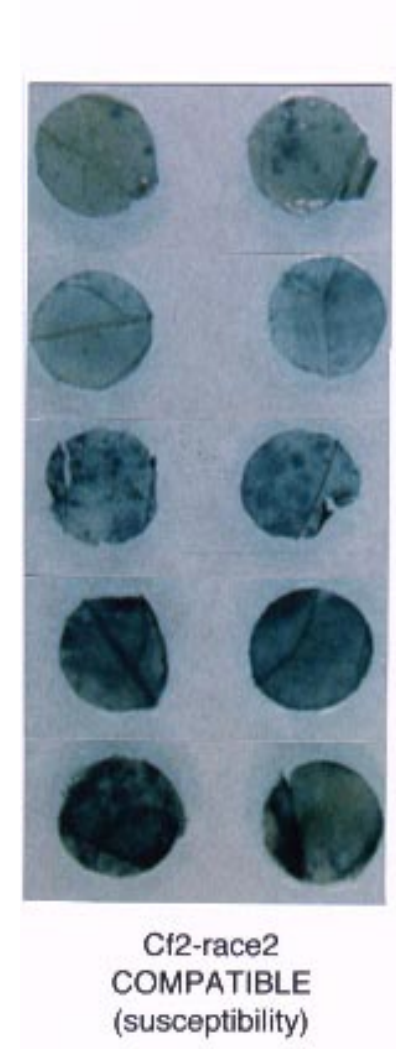

A
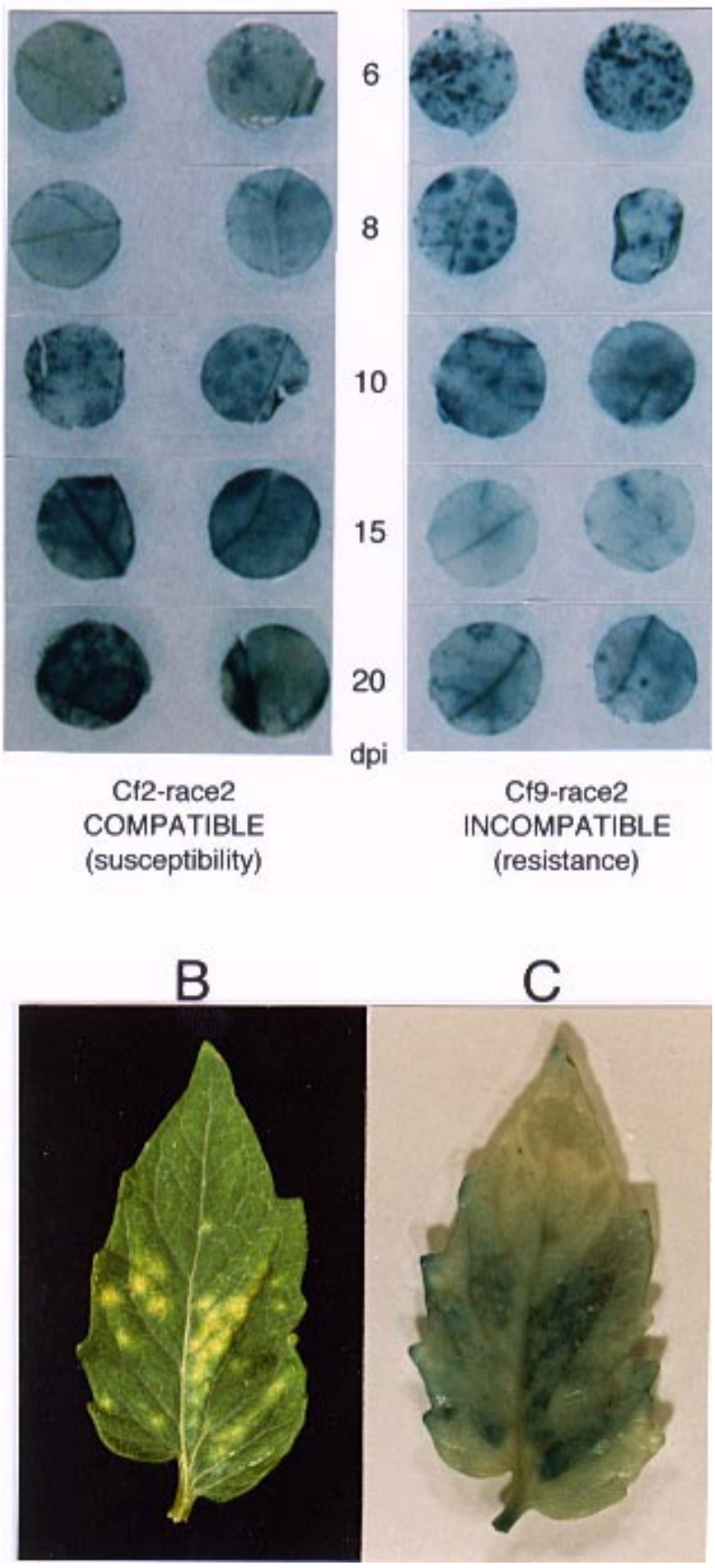

Fig. 1. Histochemical detection of the expression of the long terminal repeat- $\beta$-glucuronidase (LTR-GUS) construct in tomato after inoculation with Cladosporium fulvum. A, Kinetics of LTR-GUS expression during a Cf-9-Avr9-mediated incompatible interaction and a corresponding compatible interaction. Race 2 of C. fulvum was inoculated onto heterozygous Cf9 (resistant) and Cf2 (susceptible) plants derived from the LTR-GUS-7 transgenic line. Leaf disks were cut at different days after inoculation and tested for LTR-GUS expression. dpi = days post inoculation. B and C, Localization of LTR-GUS expression in a leaflet infected by C. fulvum 13 dpi. Analysis is carried out on a Cf2race2 (compatible) interaction similar to the one described in A. Symptoms (at upper surface of leaflet) resulting from fungal infection are shown in B; corresponding LTR-GUS expression is shown in $\mathbf{C}$. incompatible interaction mediated by the $C f-9-A v r 9$ specific recognition and a corresponding compatible interaction mediated by the same fungal race inoculated onto an isogenic tomato line carrying a different resistance gene. Figure 1A presents the GUS activity patterns observed at different time points after inoculation with race 2 of $C$. fulvum onto Cf9 (resistant) or Cf2 (susceptible) LTR-GUS transgenic tomato plants. Expression of the LTR-GUS construct is detected in both interactions, but the timing and the spatial patterns of GUS activity differ. In the compatible interaction, the GUS activity remains low up to 8 days after inoculation, and subsequently increases significantly, first in distinct spots and later over the whole leaf sample, between 10 and 15 days after inoculation. In the $C f-9-A v r 9$-mediated incompatible interaction, the GUS activity is clearly induced in distinct spots as early as 6 days after inoculation, and expression levels increase up to 10 days after inoculation. However, in contrast to the compatible interaction, in the incompatible interaction GUS activity decreases strongly between 10 and 15 days after inoculation, although a slight increase is detectable at a later stage (20 days after inoculation).

In our experimental greenhouse conditions, sporulating lesions, in compatible interactions, were detected at 15 days post inoculation, but large chlorotic lesions corresponding to massive colonization of the leaf by the fungal mycelium were observed as early as 10 days after inoculation. Histochemical GUS staining of partially colonized leaves of tomato LTRGUS transgenics shows that the GUS activity, at late stages of infection, is mostly localized in large chlorotic lesions corresponding to colonized areas. One representative example, corresponding to the expression of the LTR-GUS construct 13 days after inoculation in a compatible Cf2-race 2 interaction, is illustrated in Figure $1 \mathrm{~B}$ and $\mathrm{C}$.

\section{Kinetics of the LTR-GUS expression and comparison with the expression of tomato defense genes after inoculation with $C$. fulvum.}

The kinetics of activation of the Tnt1 promoter in inoculated leaves were also compared between another incompatible interaction mediated by the $C f-9-A v r 9$ specific recognition and a corresponding compatible interaction, by analysis of GUS biochemical activity (Fig. 2A) and steadystate transcript levels of the LTR-GUS construct (Fig. 2B). Race 4 of $C$. fulvum was inoculated onto Cf9 (resistant) or Cf4 (susceptible) LTR-GUS transgenic plants. The results confirm that the LTR-GUS construct is highly activated in the compatible interaction, between 10 and 15 days after inoculation onward (Fig. 2A and B). In the $C f-9-A v r 9$ mediated incompatible interaction, LTR-GUS transcripts are induced earlier (Fig. 2B), between 5 and 8 days after inoculation, but transcript levels are much lower than in late stages of the compatible interaction, and decrease to background levels 2 days later, although a slight increase is detectable at a later stage ( 22 days after inoculation). Only a low level of GUS activity is detectable 8 days after inoculation and onward in the incompatible interaction (Fig. 2A). No significant LTR-GUS activation is detected in control plants mock inoculated with water (Fig. 2A). However, a slight transient increase in LTR-GUS transcript levels, most probably due to the inoculation procedure, is observed immediately after inoculation (time point 0 ). 
The kinetics of LTR-GUS steady-state transcript levels were also compared with the kinetics of steady-state levels of mRNAs encoded by tomato defense genes such as the acidic and basic $\beta$-1,3-glucanase genes (Van Kan et al. 1992), the acidic and basic chitinase genes (Danhash et al. 1993), the PR-1b gene (Tornero et al. 1993; Tornero et al. 1994), and the gene encoding for phenylalanine ammonia-lyase (PAL), using a tobacco cDNA clone (Pellegrini et al. 1994). Results, presented in Figure 2B, show that LTR-GUS expression patterns parallel the expression patterns of several tomato defense genes.

In the compatible interaction, the strong increase of LTRGUS transcript levels at late stages of infection parallels the increase of basic and acidic $\beta$-1,3-glucanase (GluB and GluA) transcript levels, as well as of basic and acidic chitinase (ChiB and ChiA) transcript levels, all induced between 10 and 15 days after inoculation. Expression of the PAL and PR-1b genes is detectable at earlier stages after inoculation, but transcripts levels are enhanced between 10 and 15 days after inoculation.

During the $C f-9-A v r 9$-mediated incompatible interaction, the transient expression of the LTR-GUS construct observed 8 days after inoculation parallels the transient expression of the basic $\beta$-1,3-glucanase (GluB) gene. The timing of activation also corresponds to the stage at which expression of the basic chitinase (ChiB), PR-1b, and PAL genes is significantly enhanced, with the difference that the levels of expression of the latter three genes are maintained at later stages. A low increase of GluB, ChiB, and PR-1b transcript levels is also detectable at late stages of the incompatible interaction (22 days after inoculation), in parallel to the corresponding low increase of LTR-GUS transcript levels. Similarly, a transient activation of several tomato defense genes, especially GluB and $\mathrm{ChiB}$, is also detected immediately after inoculation. No expression of the acidic $\beta$-1,3-glucanase and chitinase (GluA and ChiA) genes was detected in our experiments.

\section{LTR-GUS activation in response to treatment with AFs of $\boldsymbol{C}$. fulvum-infected tomato plants.}

We investigated the effect of AFs obtained from $C$. fulvuminfected tomato leaves on the activity of the LTR-GUS construct, after in vitro vacuum infiltration of AFs into leaf disks of transgenic tomato lines. We tested $C f$-9-Avr9-dependent LTR-GUS expression, as well as $C f$-2-Avr2-dependent LTRGUS expression, by comparing the effect of AFs differing in the presence of AVR9 or AVR2 avirulence peptides on isogenic tomato lines containing $C f-9, C f$-2, or no resistance gene. AFs were obtained from (i) plants infected by race 0 or race 4 of $C$. fulvum (AFs $\mathrm{R} 0$ and $\mathrm{R} 4$ ), which both produce the AVR2 and AVR9 peptides, (ii) plants infected by race 2 of $C$. fulvum (AF R2), which produces the AVR9 peptide but not the AVR2 peptide, and (iii) plants infected by race 2.5 .9 of $C$. fulvum (AF R259), which produces neither the AVR2 nor the AVR9 peptide. As controls, we tested the effect of AF obtained from noninfected tomato plants (AF UC82B). Results (Fig. 3) show that, when no resistance gene is present, GUS activities observed after infiltration with the AFs R0, R2, R4, and R259 are not significantly different from background levels observed after infiltration by control AF. In various $C f-9$ Avr9 interactions (AFs R0, R2, or R4 on the Cf9 line), a 12fold mean induction of GUS activity is observed, while only
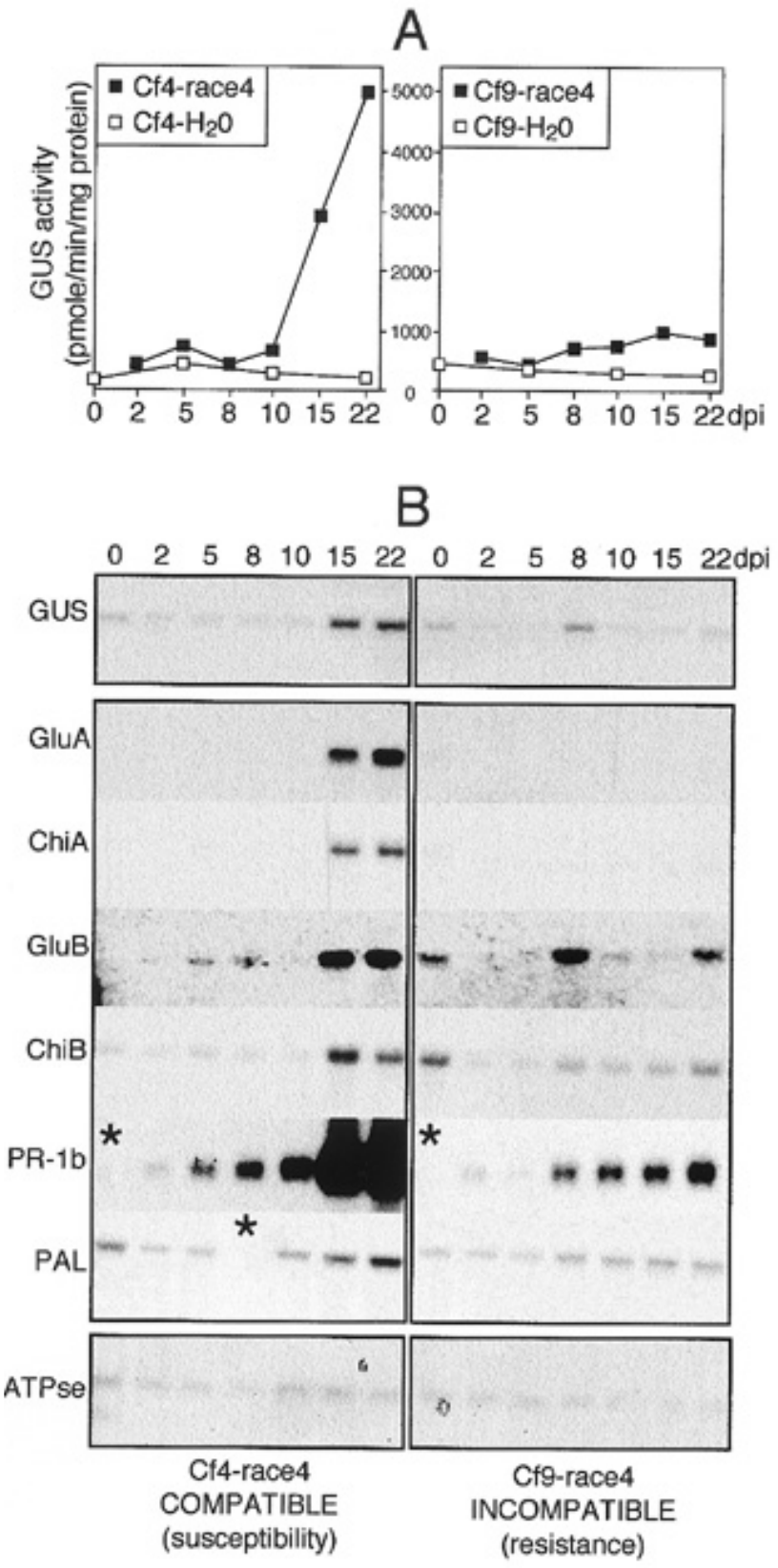

Fig. 2. Kinetics of activation of the long terminal repeat- $\beta$ glucuronidase (LTR-GUS) construct in tomato after inoculation with Cladosporium fulvum. Race 4 of C. fulvum was inoculated onto heterozygous Cf9 (resistant) and Cf4 (susceptible) tomato plants derived from the LTR-GUS-7 transgenic line. dpi = days post inoculation. A, Kinetics of GUS activity (CfX-race $4=$ plants inoculated by spraying a conidial suspension; $\mathrm{Cfx}-\mathrm{H}_{2} \mathrm{O}=$ control plants mock inoculated by spraying with water). B, Kinetics of LTR-GUS and tomato defense genes steady-state transcript levels. Probes are indicated on the left: GUS, coding domain of the GUS reporter gene; GluA and GluB, acidic and basic tomato $\beta$-1,3-glucanase cDNAs, respectively; ChiA and ChiB, acidic (Chi3) and basic (Chi9) tomato chitinase cDNAs, respectively; PR-1b, tomato pTE 28.1 cDNA; PAL, cDNA encoding the tobacco phenylalanine ammonia-lyase; ATPse, $\beta$-ATPase cDNA. Fifteen micrograms of total RNA extracted from leaves at different time points after inoculation was subjected to electrophoresis, blotted, and hybridized with the different probes, consecutively, except for the PR-1b and PAL probes, which were hybridized in separate Northern (RNA) blot experiments (*: no RNA was loaded for these time points). 
background levels are detected in the Cf9 line treated with AF $\mathrm{R} 259$, which does not contain AVR9. In various $C f-2-A v r 2$ interactions (AFs $\mathrm{R} 0$ or $\mathrm{R} 4$ on the $\mathrm{Cf} 2$ line), a fourfold mean induction of GUS activity is observed, while only background levels are detected in the $\mathrm{Cf} 2$ line treated with the AFs $\mathrm{R} 2$ or R259, which do not contain AVR2. These results indicate that higher levels of LTR-GUS activity are detected in tomato leaf tissues involving $C f-9-A v r 9$ or $C f-2-A v r 2$ interactions, demonstrating that factors derived from these specific $C f$ $A v r$ interactions are able to induce the expression of the Tnt1 promoter.

We also monitored the kinetics of LTR-GUS steady-state transcript levels after vacuum infiltration of AFs into tomato leaf disks. We tested the effect of the AFs R0, R2, and R259 on isogenic tomato lines carrying the $C f-9$ or $C f-2$ resistance gene. Results (Fig. 4) show that LTR-GUS expression increases as early as $2 \mathrm{~h}$ after vacuum infiltration. LTR-GUS expression is induced in both the presence (Fig. 4A) and absence (Fig. 4B) of a $C f-A v r$ interaction, but the kinetics of transcript accumulation differ. In the presence of a $C f$-Avr interaction, LTR-GUS expression remains high up to $48 \mathrm{~h}$ after treatment, while in the absence of such an interaction LTRGUS expression drops to background levels $24 \mathrm{~h}$ after treatment. Some expression of the LTR-GUS construct is observed immediately after infiltration (time point 0 ), and is most probably due to stress caused by infiltration, since a transient accumulation of the LTR-GUS transcript is also detected in the first hours after infiltration by control AF obtained from noninfected tomato plants (Fig. 4C).
Our results demonstrate that the expression of the LTRGUS construct in tomato is induced by components present in AFs of tomato leaves infected by $C$. fulvum, regardless of the occurrence of a $C f-A v r$ interaction. LTR-GUS transcripts, however, accumulate for a longer time after treatment with AF containing an avirulence peptide matching the resistance gene present in the treated tomato genotype. This observation shows that factors resulting from matching $C f$-Avr interaction (incompatible), as well as other factors resulting from successful infection (compatible), are involved in the activation of the Tnt1 promoter.

\section{LTR-GUS expression in response to treatment with AFs of tobacco containing the AVR9 race-specific elicitor.}

In order to analyze the response of the Tnt 1 promoter in the presence of the $C f-9-A v r 9$ interaction but in the absence of other inducing components present in the AFs of infected tomato plants, we investigated the effect of AFs obtained from a transgenic tobacco line, expressing the fungal Avr9 gene under control of the 35S promoter (Hammond-Kosack et al. 1994), on the expression of the LTR-GUS construct. This line constitutively produces high levels of the AVR9 peptide in the plant apoplast, and its AFs display the expected necrosisinducing activity upon injection in leaves of $C f$-9-carrying tomato plants (Hammond-Kosack et al. 1994). AVR9containing tobacco AF was vacuum infiltrated into leaf disks of LTR-GUS transgenic plants with or without the $C f-9$ resistance gene. Results (Fig. 5) show that, in the presence of the $C f-9$ gene, a seven- to ninefold induction of GUS activity is

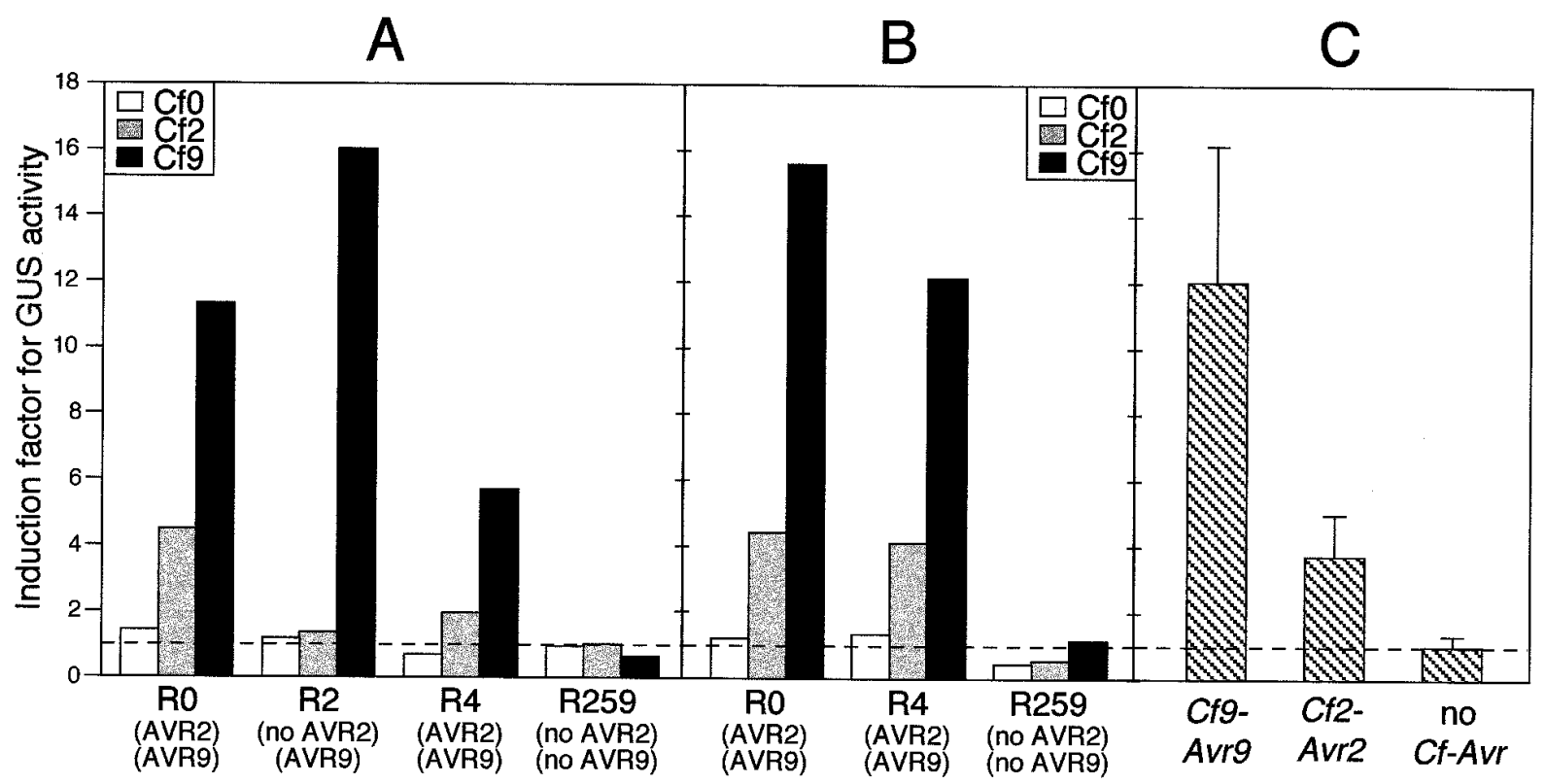

Fig. 3. Induction of long terminal repeat- $\beta$-glucuronidase (LTR-GUS) expression after treatment by apoplastic fluids (AFs) obtained from tomato plants infected by Cladosporium fulvum. Leaf disks of heterozygous Cf0, Cf2, and Cf9 plants derived from the LTR-GUS-13 transgenic line were vacuum infiltrated with different AFs (R0, R2, R4, or R259). For clarity, the presence/absence of AVR2 or AVR9 avirulence peptide is indicated for each AF. Results are expressed as induction factors, calculated as ratios between the value of the GUS activity observed after infiltration with the AF obtained from tomato plants infected by $C$. fulvum and the value of the GUS activity observed after infiltration with a control AF obtained from noninfected UC82B tomato plants. A and B, Two independent experiments. GUS activities were quantified (A) 36 or (B) $40 \mathrm{~h}$ after infiltration. C, Statistical analysis of the induction factors observed, in both experiments, in the presence of the Cf9-Avr 9 interaction (Cf9 line treated with AFs R0, R2, and R4), in the presence of the $C f 2-A v r 2$ interaction (Cf2 line treated with AFs R0 and R4), and in the absence of any $C f$-Avr interaction (Cf0 line treated by AFs R0, R2, R4, and R259; Cf2 line treated by AFs R2 and R259; Cf9 line treated with AF R259). Each bar represents the mean induction factor; standard deviations are indicated by vertical lines. Dotted line indicates an induction factor of 1 . 
observed after treatment with this AF, compared with GUS activities observed after treatment with a control AF obtained from nontransgenic tobacco plants. No significant induction is detected in $\mathrm{CfO}^{\prime}$ or $\mathrm{Cf} 4$ lines after treatment with the AVR9containing tobacco AF, confirming that this induction is specifically mediated by factors derived from the $C f-9-A v r 9$ specific interaction.

\section{Comparison of the LTR-GUS expression with the expression of tomato defense genes in response to treatments with AFs.}

The differential accumulation pattern of LTR-GUS transcripts in the presence or absence of $C f-9-A v r 9$ specific recognition was compared with the accumulation patterns of transcripts encoded by tomato defense genes. Results (Fig. 6) show that the basic $\beta$-1,3-glucanase gene is expressed several hours later than the LTR-GUS construct. The pattern of expression of the basic $\beta-1,3$-glucanase gene in the $C f-9-A v r 9$ interaction (Fig. 6A) is, however, similar to its pattern of expression in tomato tissues treated with control AF UC82B obtained from noninfected tomato plants (Fig. 6C), demonstrating that expression of the basic $\beta$-1,3-glucanase gene results mostly from the wounding/infiltration process. In contrast to basic $\beta$-1,3-glucanase transcripts, PAL transcripts are detected immediately after infiltration. Transcript levels, however, decrease rapidly during the first hours after infiltration with the control AF (Fig. 6C). Early induction of PAL by the wounding/infiltration process is thus more similar to LTRGUS early induction, with the difference that PAL transcripts remain detectable over a longer period of time after infiltration. PAL expression, however, is strongly induced, and re- mains high up to $48 \mathrm{~h}$ after treatment with AFs obtained from infected tomato plants (Fig. 6A and B). However, in contrast to LTR-GUS expression, the expression patterns of the PAL gene appear independent of the presence (Fig. 6A) or absence (Fig. 6B) of the $C f-9-A v r 9$ interaction.

\section{DISCUSSION}

Tnt1 expression after inoculation with $C$. fulvum parallels the biological response of the plant to fungal inoculation.

The expression of the Tnt 1 retrotransposon was previously shown to be activated by viral and bacterial pathogens (Moreau-Mhiri et al. 1996; Grandbastien et al. 1997). In this work, we report that Tnt 1 expression is also activated by a fungal pathogen. We have analyzed the patterns of Tnt1 expression in compatible and incompatible plant-fungus interactions of the same gene-for-gene pathosystem, and we have compared these patterns with those of plant defense responses activated during these interactions. We show that Tnt 1 is differentially activated and that Tnt 1 activation patterns correlate with the differential activation patterns of plant defense genes, thus demonstrating that Tnt 1 expression parallels the biological response of the plant to the fungal attack.

The activation of the Tnt 1 promoter was studied in tomato after inoculation with virulent and avirulent races of the fungal pathogen $C$. fulvum. Tnt1 expression is induced in both compatible and $C f-9-A v r 9$-mediated incompatible interactions, but expression patterns are different. In compatible interactions, a high level of activation of the Tnt 1 promoter is found at late stages of infection only, which are associated with the final stages of massive leaf colonization and sporula-

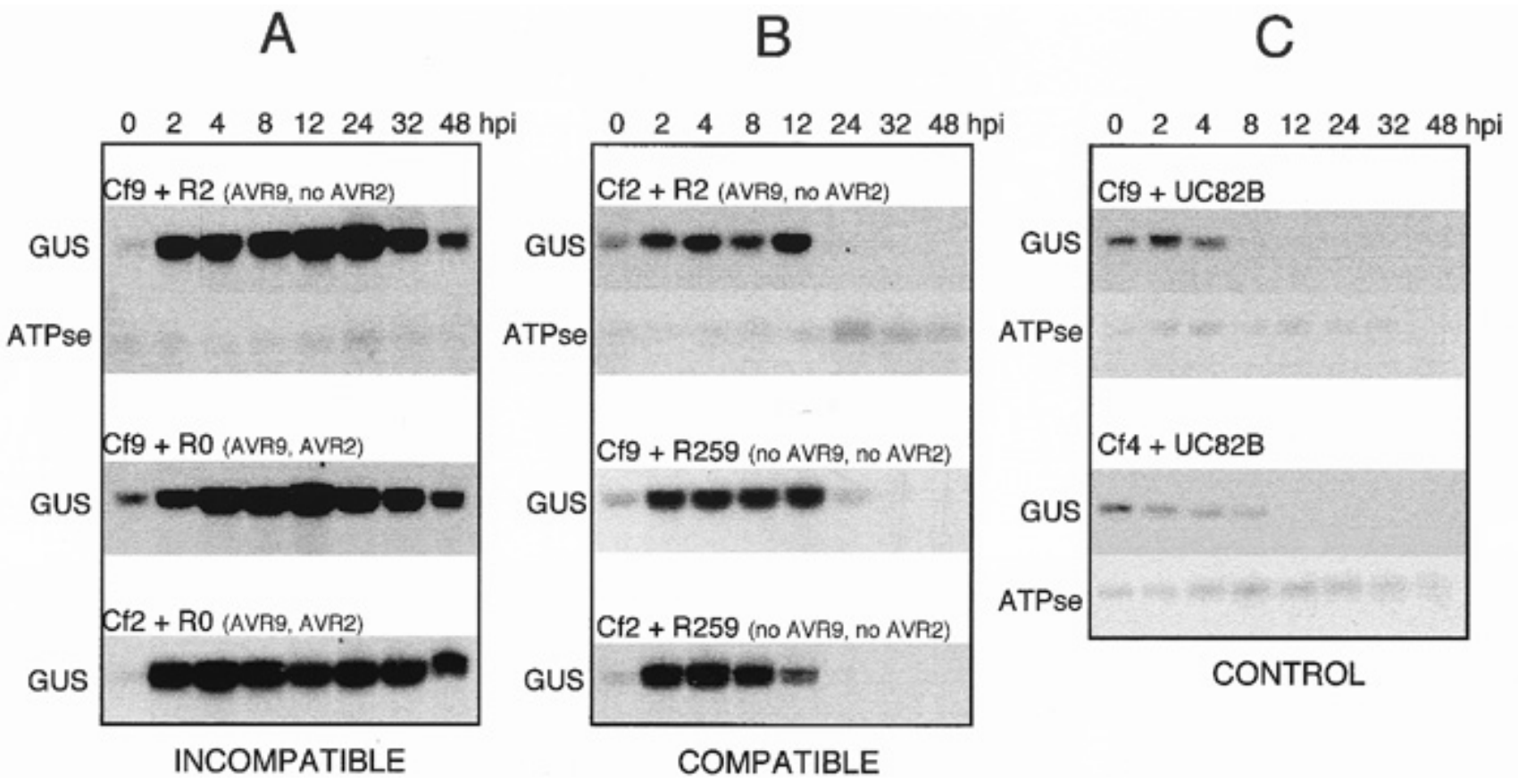

Fig. 4. Kinetics of long terminal repeat- $\beta$-glucuronidase (LTR-GUS) steady-state transcript levels in response to apoplastic fluids (AFs) obtained from tomato plants infected by Cladosporium fulvum. Leaf disks of heterozygous Cf0, Cf2, and Cf9 plants derived from the LTR-GUS-13 transgenic line were vacuum infiltrated with different AFs (R0, R2, or R259). For clarity, presence/absence of AVR2 or AVR9 avirulence peptide is indicated for each AF. UC82B is a control AF obtained from noninfected UC82B tomato plants, and was tested on Cf9 and Cf4 lines. Plant genotype and fluid tested are indicated above each Northern (RNA) blot. Total RNA was analyzed at different times after infiltration (hpi = hours post infiltration). At each time point, 15 $\mu \mathrm{g}$ of total RNA was subjected to electrophoresis, blotted, and hybridized with the GUS or ATPase probe (see Figure 2), consecutively. 
tion. This induction is detected throughout the whole leaf area where fungal growth has extended. However, in incompatible interactions, the activation of the Tnt1 promoter is induced earlier but transiently and remains localized to distinct foci.

The spatial and temporal expression patterns of Tnt 1 show striking similarities with the expression patterns of the gnl $\beta$ 1,3-glucanase gene of Nicotiana plumbaginifolia, whose expression was studied, with a gnl:GUS fusion, in tomato plants inoculated with $C$. fulvum (Ashfield et al. 1994). Expression of the gnl:GUS fusion is detectable only during late stages of compatible interactions, in large patches coinciding with fungal growth, while expression of the gnl:GUS fusion in incompatible interactions is induced earlier and remains localized in distinct foci. These latter foci were shown to correspond to the sites of $C$. fulvum penetration, where hyphal growth was arrested (Ashfield et al. 1994). These similarities between Tnt1 expression patterns and those of the gn1:GUS fusion suggest that local Tnt1 activation during the early stages of an incompatible interaction might also coincide with the sites of fungal penetration and restricted colonization.

Tnt1 expression after inoculation with $C$. fulvum parallels the expression of tomato defense genes. During successful infections, both Tnt 1 expression and the expression of tomato defense genes, especially PR protein genes such as $\beta-1,3-$

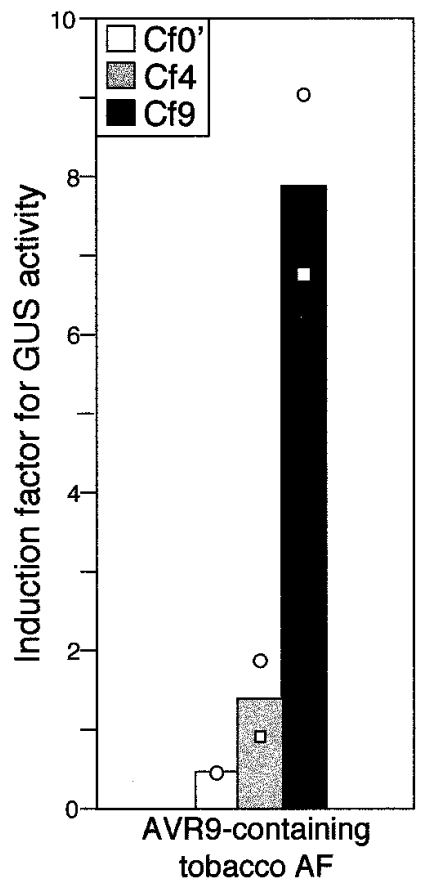

Fig. 5. Induction of long terminal repeat- $\beta$-glucuronidase (LTR-GUS) expression after treatment by apoplastic fluids (AFs) of tobacco containing the AVR9 race-specific elicitor. Leaf disks of heterozygous Cf0, Cf4, and Cf9 plants derived from the LTR-GUS-3 transgenic line were vacuum infiltrated with AF obtained from the transgenic SLJ6201A tobacco line, producing the AVR9 peptide in the apoplast. Results are expressed as induction factors, calculated as ratios between the value of the GUS activity observed after infiltration with AF obtained from the SLJ6201A tobacco line and the value of the GUS activity observed after infiltration with AF obtained from the control XHFD8 tobacco line. GUS activities were quantified $48 \mathrm{~h}$ after infiltration. Induction factors are indicated by symbols and means are shown by bars. Each symbol corresponds to an independent experiment. glucanase and chitinase, are induced at late stages coinciding with massive fungal growth in the plant. In incompatible interactions involving the complementary $C f-9$ and $A v r 9$ genes, Tnt1 expression is transiently induced, coinciding with the induction of the expression of several tomato defense genes. A slight activation of Tnt 1 expression, and of several tomato defense genes, is also reproducibly detected at the latest stages of infections in incompatible interactions. This was not, and could never be, observed in previous studies reported in the literature, as the infections were never followed for as long. We have no explanation for this seemingly late increase in expression.

Our results on the timing of the expression of tomato defense genes during the tomato- $C$. fulvum interaction are slightly different from previous studies (Van Kan et al. 1992; Danhash et al. 1993). However, the activation of tomato defense mechanisms varies between different $C f-A v r$ interactions (Ashfield et al. 1994; Hammond-Kosack et al. 1996), which hampers easy comparisons. Some differences may also be explained by different greenhouse conditions, shown to influence infection by the fungus (De Wit 1977), and by the hemizygous state, in our study, of the semidominant $C f$ resistance genes (Ashfield et al. 1994; Hammond-Kosack and Jones 1994). In addition, plant responses might be influenced by additional parameters such as the fungal race or differences in plant physiological states, since slight shiftings in the timing of overall LTR-GUS responses, in both compatible and incompatible interactions, were observed between independent inoculation experiments performed with different fungal races (race 2, Fig. 1; and race 4, Fig. 2).

Nevertheless, our results clearly show that there is a correlation between the differential expression of Tnt 1 and the differential biological response of the plant to fungal infection by virulent or avirulent races, both in terms of symptoms resulting from the infection and in terms of induction of plant defense gene expression.

\section{Tnt1 expression is induced by several specific and nonspecific factors present in leaves of tomato plants infected by $C$. fulvum.}

Although Tnt1 expression was shown to be activated by several abiotic and microbial factors (Moreau-Mhiri et al. 1996; Mhiri et al. 1997), little was known of the triggers involved. We exploited the experimental advantages provided by the tomato- $C$. fulvum system, such as the possibility of in vitro assays to mimic plant-fungus interactions, to obtain a better understanding of the factors involved in the transcriptional activation of Tnt 1 during infection by $C$. fulvum.

AFs of $C$. fulvum-infected leaves contain fungal racespecific elicitors and are known to induce $C f$-dependent defense responses when injected into tomato leaves (De Wit and Spikman 1982; Ashfield et al. 1994; Hammond-Kosack et al. 1996; May et al. 1996; Wubben et al. 1996). AFs also contain many nonspecific factors of plant and fungal origin generated during massive colonization of leaf tissue. A clear induction of Tnt1 expression is observed after treatment with AFs derived from $C$. fulvum-infected tomato leaves, regardless of the presence in these AFs of avirulence peptides matching the products of the resistance genes present in the tested plant. Thus, Tnt1 expression can be induced by nonspecific factors present in AFs of infected leaves. We propose that this non- 
specific induction could be caused by factors similar to those involved in Tnt1 activation during late stages of successful infections. As we have observed that C. fulvum culture filtrates are able to induce the expression of the LTR-GUS construct (C. Mhiri, unpublished), these factors might be fungusderived products. In addition, plant signal molecules produced during infection could be involved. Activation of the Tnt1 promoter by nonspecific factors in AFs is transient, suggesting that the signals involved are rapidly inactivated in the absence of the fungus.

However, activation of the LTR-GUS construct by nonspecific factors in AFs is transient and does not result in significant accumulation of the GUS protein. The highest contribution to the GUS activity detected 36 to $40 \mathrm{~h}$ after AF treatments is $C f$ dependent, and results from specific interactions between fungal avirulence peptides and products of the corresponding plant resistance genes. This was clearly confirmed in the case of the $C f-9-A v r 9$ interaction, since AFs containing the AVR9 peptide (AF isolated from Avr9 transgenic tobacco), but no other products resulting from the tomato- $C$. fulvum interaction, mediate a $C f-9-$ specific activation of the Tnt1 promoter. Induction factors for GUS activity observed for the $C f-2-A v r 2$ interaction are lower than those observed for the $C f-9-A v r 9$ interaction, in agreement with previous observations that the activation of defense responses varies between different $C f-A v r$ interactions (Ashfield et al. 1994; Hammond-Kosack et al. 1996). Tnt1 $C f$-dependent ex- pression is detected up to $48 \mathrm{~h}$ after matching AVR-elicitor treatment, suggesting that the signals involved are either more stable than those involved in Tnt1 activation by nonspecific factors, or are produced at later stages of the biochemical pathway activated upon $C f$-Avr recognition. The $C f$-dependent expression of Tnt 1 observed after treatment with matching AVR-elicitor-containing AFs confirms that the local and transient expression of Tnt 1 observed after inoculation with an avirulent fungal race could be caused by factors produced or released as a result of interaction between the resistance and avirulence gene products at the site of fungal penetration. However, due to the rapid restriction of fungal growth resulting from the HR of the plant, Tnt1 activation after inoculation with an avirulent race remains localized and results from the effect of the avirulence peptide on a limited number of leaf cells only. This explains why LTR-GUS transcripts appear to accumulate at low levels in whole leaves after inoculation with an avirulent fungal race, while in vitro massive application of matching AVR-elicitor-containing fluids activates Tnt1 $C f$-dependent expression at high levels.

Taken together, our results show that transcriptional activation of Tnt 1 during the tomato-C. fulvum interaction is mediated by different perception systems, one that recognizes nonspecific fungal- or plant-derived signals produced during successful infections, and an additional one derived from the specific interaction between avirulence and resistance gene products occurring during an incompatible interaction. The

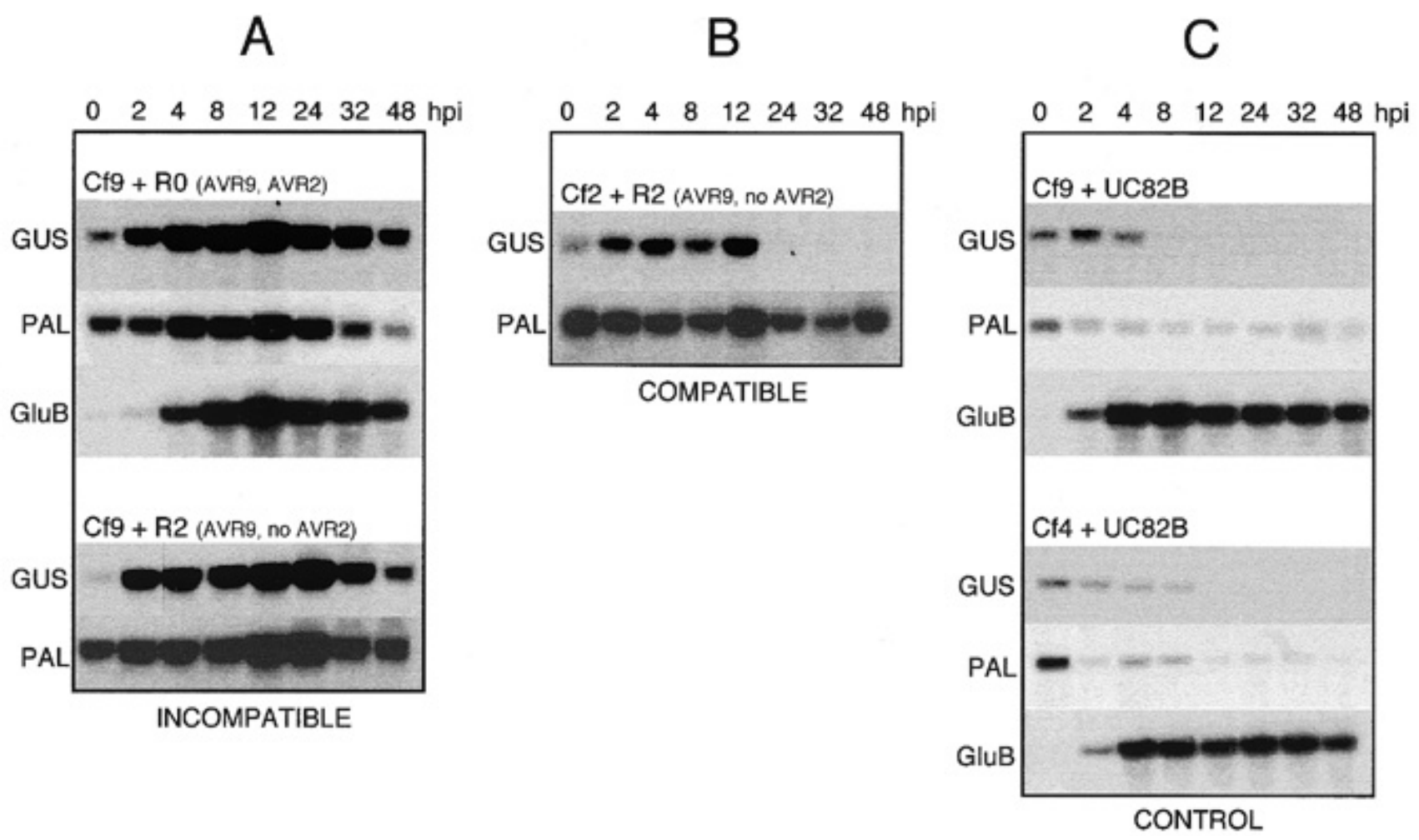

Fig. 6. Comparison of the kinetics of long terminal repeat- $\beta$-glucuronidase (LTR-GUS) steady-state transcript levels, in response to apoplastic fluids (AFs) obtained from tomato plants infected by Cladosporium fulvum, with the kinetics of steady-state transcript levels of tomato defense genes. Leaf disks of heterozygous Cf9 and Cf2 plants derived from the LTR-GUS-13 transgenic line were vacuum infiltrated with elicitor-containing apoplastic fluids (AFs). For clarity, presence/absence of AVR2 or AVR9 avirulence peptide is indicated for each AF. UC82B is a control AF obtained from noninfected UC82B tomato plants, and was tested on Cf9 and Cf4 lines. Total RNA was analyzed at different times after infiltration (hpi $=$ hours post infiltration). Probes are indicated on the left (for details see Figure 2). At each time point, $15 \mu \mathrm{g}$ of total RNA was subjected to electrophoresis, blotted, and hybridized with the different probes, consecutively. 
first system might involve one or several receptor(s), recognizing, for instance, oligosaccharides derived from fungal or plant cell walls (Ryan and Farmer 1991), while the second system might involve putative binding of the AVR-peptide elicitor to a specific receptor.

\section{Tnt1 expression is an early marker of the plant defense response.}

Plant defense genes have been divided into two classes (Baillieul et al. 1995): class I comprises genes expressed soon after elicitation and involved in early steps of the phenylpropanoid pathway such as the PAL or OMT (orthodiphenol-Omethyltransferase) genes; and class II comprises PR protein genes induced several hours later, possibly by salicylic acid or other plant signals resulting from the activation of the phenylpropanoid pathway. Overall kinetics of transcript accumulation after fungal inoculations show that Tnt1 expression correlates with the expression of several tomato defense genes, including PR protein genes. Detailed kinetics obtained after AF treatments show, however, that Tnt 1 expression is induced several hours earlier than the expression of the basic $\beta-1,3-$ glucanase PR protein gene. Furthermore, activation of the latter does not result from the effect of AF components, but is a consequence of the wounding/infiltration process. Tnt 1 expression is more similar to the expression of the PAL gene, which is also activated early after treatment with AFs, and only transiently by infiltration. However, activation of the PAL gene appears independent of the $C f-9-A v r 9$ interaction, in contrast to Tnt1 $C f$-dependent activation. Specific recognition between avirulence and resistance gene products in the tomato- $C$. fulvum interaction has been shown to result in the activation of early defense responses, such as production of reactive oxygen species (ROS) a few hours after elicitation with AFs (Vera-Estrella et al. 1992; May et al. 1996), as well as production of ethylene and salicylic acid a few hours later (Hammond-Kosack and Jones 1996). Since Tnt1 transcription in tomato is activated by ROS and by salicylic acid (Mhiri et al. 1997) it is possible that Tnt1 transcriptional activation, which is detectable $2 \mathrm{~h}$ after elicitation with AFs, is triggered by ROS generated soon after recognition of the elicitor molecule by the host. Interestingly, PAL activation appears to be independent of the occurrence of oxidative burst (Lamb and Dixon 1997). Our results thus show that Tnt1 can be considered a class I marker of the plant defense response, but that some of the molecular signals involved in Tnt1 activation differ from those involved in the activation of the PAL gene, and might result more directly from oxidative burst.

The molecular basis of Tnt 1 regulation is presumably linked to the presence, in its LTR, of several motifs that show homologies to cis-regulatory sequences of plant defense genes (Casacuberta and Grandbastien 1993; Mhiri et al. 1997), some of which are involved in Tnt 1 activation by microbial elicitors or by stress (Casacuberta and Grandbastien 1993; Vernhettes et al. 1997). Interestingly, other plant retrotransposons, such as Tto 1 or Tto5 of tobacco, are also activated by viral infections and intermediates of plant defense responses (Hirochika 1995; Takeda et al. 1998). Tto1 activation also involves LTR motifs that show homologies to defense gene regulatory motifs (Hirochika 1997). It thus appears that the activation of these two plant retrotransposons is tightly linked to molecular pathways activated by biotic and abiotic stress and they can be considered sensitive markers of plant defense. However, the biological significance of their regulation as well as the origin of their regulatory sequences remain obscure. As these elements do not encode functions other than those required for their mobilization, it seems difficult to imagine a direct role for element-encoded functions in defense responses. Transposable elements are a major source of genetic variation, which ranges from chromosomal alterations up to fine tunings of the expression of cellular genes. As originally proposed by McClintock (1984), the activation of transposable elements by stress might be involved in host adaptation to environmental challenges and give the host plant a selective advantage in evolution. Alternatively, Tnt1-specific regulation might simply contribute to avoidance of uncontrolled potentially hazardous transposition events by restricting the element's activity to rare but stressful situations. A third alternative, however, would be that transposon activation by pathogen infections might favor possible horizontal transfers from plants to pathogens, thus allowing the element to spread into new hosts. Retrotransposon mobility is linked to the production of cytoplasmic transposition intermediates such as viruslike particles or free DNA molecules. The demonstration that Tnt1 transcriptional activation reaches high levels at late stages of infection by a pathogen such as $C$. fulvum, which interacts with many plant cells, thus represents a very useful model system to test for the possibility of horizontal transfer of transposable elements between phylogenetically unrelated organisms.

\section{MATERIAL AND METHODS}

\section{Fungal strains.}

Cladosporium fulvum Cooke (syn. Fulvia fulva (Cooke) Cif.) race 0 (isolate Sarrians), race 2 (isolate Ovakoy), race 4 (isolate La Maxe 2), race 5 (isolate St. Martin de Crau) and race 259 (isolate Brest Rianto) were kindly provided by $\mathrm{H}$. Laterrot (INRA, Avignon, France). C. fulvum isolates were subcultured every month on fresh $\mathrm{S}$ medium (Messiaen and Lafon 1970) as described in Laterrot and Clerjeau (1979). Fungal cultures were grown at $25^{\circ} \mathrm{C}$ under a 12 -h photoperiod $\left(50 \mu \mathrm{E} \cdot \mathrm{s}^{-1} \cdot \mathrm{m}^{-2}\right)$ delivered by white and near-UV tubes (Sylvania, Puteaux, France).

\section{Plant material.}

Near-isogenic lines (NILs) of Lycopersicon esculentum cv. Moneymaker homozygous for the resistance genes $C f-2, C f-4$, and $C f$-9 (Tigchelaar 1984) were obtained from K. H. Hammond-Kosack (John Innes Institute, Norwich, England) for NILs containing the $C f-2$ gene $(C f 2$ NIL), and from R. P. Oliver (University of East Anglia, Norwich, England) for the NILs containing the $C f-4$ and $C f-9$ genes (Cf4 and $C f 9$ NILs), as well as the Moneymaker $C f O$ NIL lacking all known $C f$ genes.

LTR-GUS transgenic tomato plants were described previously (Moreau-Mhiri et al. 1996; Mhiri et al. 1997). Three independent transformants, LTR-GUS-3, LTR-GUS-7, and LTR-GUS-13, carrying one copy of the T-DNA transgene were used in this study. The genetic background of these tomato transformants (cv. UC82B) lacks any known resistance gene, since they are successfully infected by $C$. fulvum race 0 . These transformants will therefore be referred to as $\mathrm{CfO}^{\prime}$ genotypes. 
Homozygous $\mathrm{T}_{3}$ LTR-GUS CfO' transgenics were crossed with the $C f O$ or $C f 2$ NILs, while $\mathrm{T}_{2}$ heterozygous LTR-GUS Cf0' transgenics were crossed with the $C f 4$ or $C f 9$ NILs. In the latter cases, segregants containing the LTR-GUS transgene were screened by histochemical GUS staining. Small cotyledon pieces were elicited overnight in a $1 \mathrm{mg}$ of Onozuka per $\mathrm{ml}$ solution and screened for the presence of a blue coloration indicative of the presence of the LTR-GUS construct (Moreau-Mhiri et al. 1996). LTR-GUS tomato transgenics carrying $C f$ genes were therefore heterozygous for both the LTRGUS construct and the $C f$ gene. In this work, LTR-GUS lines obtained from crosses of the $\mathrm{CfO}^{\prime}$ transgenics with Moneymaker NILs, and containing the $C f-2, C f-4$, or $C f-9$ genes, or no resistance gene, are referred to as $\mathrm{Cf} 2, \mathrm{Cf} 4, \mathrm{Cf} 9$, and $\mathrm{Cf0}$, respectively. $\mathrm{T}_{2}$ heterozygous LTR-GUS CfO' transgenic individuals were also used directly in some experiments.

The transgenic tobacco (Nicotiana tabacum) line SLJ6201A overexpressing a synthetic AVR9 peptide in the apoplast (Hammond-Kosack et al. 1994) was kindly provided by K. E. Hammond-Kosack and J. D. G. Jones (John Innes Institute, Norwich, UK).

The tomato cultivar UC82B and the tobacco line XHFD8 (Bourgin and Missonier 1973) were also used as controls in this study.

\section{Plant growth and inoculation.}

Tomato plants were grown in plastic pots under greenhouse conditions. C. fulvum conidial suspensions from 3-week-old fungal cultures were prepared in sterile water. Pots containing 6- to 7-week-old plants with four fully expanded leaves were transferred into polyethylene-covered boxes containing a bed of humidified compost and inoculated the same day by spraying a conidial suspension of $5 \times 10^{5}$ spores $\cdot \mathrm{ml}^{-1}$ onto the lower surfaces of leaves $2,3,4$, numbered according to leaf appearance. Mock inoculations were performed by spraying water. Plants were incubated for 3 days to maintain humidity to saturation. Subsequently, the relative humidity was reduced by slightly opening the lid. Beds of compost were watered once daily to maintain high humidity in boxes. For each experiment, inoculation was performed by inoculating eight plants per genotype per $C$. fulvum isolate. For Northern (RNA) blot experiments, two to three leaves from different plants were collected, frozen in liquid nitrogen, and stored at $-80^{\circ} \mathrm{C}$. For GUS assays, $1-\mathrm{cm}$-diameter leaf disks, cut with a cork borer, were collected from inoculated leaves of different plants for each time point, and treated as described below. Disks from resistant plants (incompatible interaction) were cut from random positions on inoculated leaves, and disks from susceptible plants (compatible interaction) were cut from random positions on inoculated leaves prior to the appearance of symptoms (6 to 10 days post inoculation) or were cut from colonized leaf regions after the appearance of symptoms (15 days post inoculation and onward). In some cases, partially colonized leaflets were collected in full, and monitored for GUS histochemical coloration.

\section{Isolation of AFs and assays}

for their biological activity.

Infected leaflets of susceptible tomato plants were harvested 15 days after inoculation with C. fulvum and AFs were isolated as described (De Wit and Spikman 1982), aliquoted, and stored at $-20^{\circ} \mathrm{C}$. The AF R0, obtained after infection of the Moneymaker $C f O$ NIL by $C$. fulvum race 0 , was kindly provided by K. E. Hammond-Kossack (John Innes Institute, Norwich, UK). The AFs R2 and R4 were obtained after infection of the UC82B tomato line by C. fulvum race 2 and race 4, respectively. The AF R259 used for GUS biochemical analyses (Fig. 3) was obtained after infection of the UC82B tomato line by $C$. fulvum race 2.5.9, and the AF R259 used for LTRGUS transcript analyses (Fig. 4) was obtained after infection of the Moneymaker Cf5 NIL by $C$. fulvum race 2.5.9. Control AFs were obtained in a similar way from healthy UC82B plants. Tobacco AFs were obtained in a similar way from the SLJ6201A tobacco line overexpressing the AVR9 peptide and from the nontransgenic XHFD8 tobacco line.

To test for the activity of the AFs R0, R2, and R4, as well as the AF obtained from the SLJ6201A tobacco line, leaflets of homozygous $C f 9$ NILs plants were injected with an AF dilution series ranging from $1 / 2$ to $1 / 32$, as described in De Wit and Spikman (1982). Chlorosis and/or necrosis were scored 8 days later. Since the LTR-GUS lines used in our studies were heterozygous for the semidominant resistance gene (Hammond-Kosack and Jones 1994), the AF dilutions used in our infiltration experiments were twofold lower than the minimal dilution that induced necrosis in homozygous $C f 9$ NILs. We used a dilution of $1 / 4$, except for AF R2 (1/8). These dilutions were also shown to be effective in inducing necrosis after injection into Cf9 heterozygous LTR-GUS lines. The two AFs R259 were used at a dilution 1/4, as well as the tomato and tobacco control AFs.

\section{Tomato leaf sampling and elicitor treatment.}

One-centimeter-diameter leaf disks, cut with a cork borer, were vacuum infiltrated with diluted AFs, dried on absorbent paper, and kept in the dark in petri dishes on Whatman disks humidified with distilled water. At different time points after vacuum infiltration, two or four disks were collected, for GUS assays and for Northern blot analyses, respectively. For GUS assays, two leaflets originating from different plants were used per genotype in each experiment. In order to randomize results, a number of disks identical to the number of tested AFs were cut from each leaflet. In each experiment, disks collected from leaves of two different plants were pooled and two sets of identical disks originating from the same leaflet were thus treated with different AFs. In each experiment, analyses with a given AF were performed in one unique infiltration experiment. For Northern blot analyses, disks collected from leaves of four different plants were pooled for each time point, and two different kinetics were performed in each experiment.. Before freezing, disk borders were removed by a smaller cork borer (4 $\mathrm{mm}$ smaller in diameter) or a scalpel in order to eliminate the local activation of Tnt1 expression by wounding (Mhiri et al. 1997). Samples were frozen in liquid nitrogen and stored at $-80^{\circ} \mathrm{C}$.

\section{GUS assays.}

After grinding, leaf tissues were resuspended in phosphate buffer $\left(50 \mathrm{mM} \mathrm{NaH} \mathrm{PO}_{4}, 2 \mathrm{H}_{2} \mathrm{O}, 10 \mathrm{mM}\right.$ EDTA, $10 \mathrm{mM}$ dithiothreitol [DTT], pH7). Protein concentration in the extracts was estimated according to Bradford (1976). GUS activity was measured following the protocol of Jefferson et al. (1987). For histochemical assays, plant material was vacuum 
infiltrated with $1 \mathrm{mM}$ 5-bromo-4-chloro-3-indolyl $\beta$-D-glucuronic acid (X-gluc; Biosynth AG, Staad, Switzerland) in 0.1 $\mathrm{M}$ phosphate buffer, $\mathrm{pH}$, containing $5 \mathrm{mM}$ potassium ferriand ferrocyanide and incubated overnight at $37^{\circ} \mathrm{C}$. Chlorophyll was removed from tissues by clearing in $70 \%$ ethanol.

\section{Molecular probes and transcript analyses.}

Tomato cDNA clones encoding the P35 acidic (GluA) and P35 basic (GluB) $\beta-1,3$ glucanase genes have been described previously (Van Kan et al. 1992), as well as the P26 acid (ChiA) and P30 basic (ChiB) chitinase genes (Danhash et al. 1993). These four clones were digested with BamHI and XhoI, and cDNA fragments (GluA: $1.2 \mathrm{~kb}$; GluB: $1.3 \mathrm{~kb}$; ChiA: 0.9 $\mathrm{kb}$, ChiB: $1 \mathrm{~kb}$ ) were purified on agarose gel. The basic tomato PR-1b (pTE 28-1) and the acidic tobacco PAL.E cDNA clones used in these studies were those described by Tornero et al. (1993) and Pellegrini et al. (1994), respectively. The PAL.E 2.4-kb EcoRI fragment and the PR-1b 0.8-kb $E c o \mathrm{RI} / \mathrm{XhoI}$ fragment were purified on agarose gel before labeling. To test for equal loading, a $\beta$-ATPase cDNA fragment (Boutry and Chua 1985) was used as a constitutive control.

Total RNA was extracted following the protocol of Logemann et al. (1987). RNA was separated on denaturing $1.5 \%$ agarose gel and transferred to a Hybond $\mathrm{N}$ membrane (Pharmacia Amersham BioTech, Orsay, France). An oligolabeling kit (Pharmacia Amersham BioTech) was used to label the probes with $\alpha-{ }^{32} \mathrm{P}-\mathrm{dCTP}$ from DuPont NEN (Paris, France). Hybridization was carried out at $42^{\circ} \mathrm{C}$ in $50 \%$ formamide, $6 \times \mathrm{SSC}(1 \times \mathrm{SSC}$ is $0.15 \mathrm{M} \mathrm{NaCl}$ plus $0.015 \mathrm{M}$ sodium citrate), $0.5 \%$ SDS (sodium dodecyl sulfate), $5 \times$ Denhardt's, $100 \mu \mathrm{g}$ of calf thymus DNA per ml. Membranes were washed at a maximum stringency of $0.1 \times \mathrm{SSC}, 0.1 \% \mathrm{SDS}$ at $65^{\circ} \mathrm{C}$.

\section{ACKNOWLEDGMENTS}

We are very much indebted to Kim E. Hammond-Kossack and to Jonathan D. G. Jones for their very helpful advice and for the kind gift of the tobacco SLJ6201 transgenic line, as well as of tomato NILs and AF preparations. We are also grateful to Richard P. Oliver, who was the stimulating factor behind these studies and who provided us with tomato NILs and showed us how to prepare apoplastic fluids, and to Henri Laterrot who provided us with the fungal races and with advice on fungal storage and infection experiments. We also thank our colleagues from the Station de Phytopathologie (INRA Versailles), Mylene Balesdent and Thierry Rouxel, who kindly hosted us and counseled us about fungal cultures. We are very grateful to Jean Marie Pollien for technical assistance in the greenhouse. This work was funded partly by the BRIDGE contract BIOT-CT91-0287 from the EEC and by the R94/48 contract from the MAP. C. M. was supported by a fellowship from the MRES.

\section{LITERATURE CITED}

Ashfield, T., Hammond-Kosack, K. E., Harrison, K., and Jones, J. D. G. 1994. $C f$ gene-dependent induction of a $\beta$-1,3-glucanase promoter in tomato plants infected with Cladosporium fulvum. Mol. PlantMicrobe Interact. 7:645-657.

Bailey, J. A. 1982. Mechanisms of phytoalexin accumulation. Pages 289-318 in: Phytoalexins. J. A. Bailey and J. W. Mansfield, eds. Halsted, Wiley, New York.

Baillieul, F., Genetet, I., Kopp, M., Saindrenan, P., Fritig, B., and Kauffmann, S. 1995. A new elicitor of the hypersensitive response in tobacco: A fungal glycoprotein elicits cell death, expression of defence genes, production of salicylic acid, and induction of systemic acquired resistance. Plant J. 8:551-560.

Boeke, J. D., and Corces, V. G. 1989. Transcription and reverse transcription of retrotransposons. Annu. Rev. Microbiol. 43:403-434.

Bol, J. F., Linthorst, H. J. M., and Cornelissen, B. J. C. 1990. Plant pathogenesis-related proteins induced by virus infection. Annu. Rev. Phytopathol. 28:113-138.

Bourgin, J. P., and Missonier, C. 1973. Vegetative propagation and cold preservation of haploid plants of Nicotiana tabacum and Nicotiana paniculata. Haploid Inf. Serv. 8:7.

Boutry, M., and Chua, N. H. 1985. A nuclear gene encoding the beta subunit of the mitochondrial ATP synthase in Nicotiana plumbaginifolia. EMBO J. 4:2159-2165.

Bowles, D. J. 1990. Defense-related proteins in higher plants. Annu. Rev. Biochem. 59:873-907.

Bradford, M. M. 1976. A rapid and sensitive method for the quantification of microgram quantities of utilizing the principle of protein dye binding. Anal. Biochem. 72:248-254.

Bradshaw, V. A., and McEntee, K. 1989. DNA damage activates transcription and transposition of yeast Ty retrotransposons. Mol. Gen. Genet. 218:465-474.

Casacuberta, J. M., and Grandbastien, M.-A. 1993. Characterisation of LTR sequences involved in the protoplast specific expression of the tobacco Tnt1 retrotransposon. Nucleic Acids Res. 21:2087-2093.

Danhash, N., Wagemakers, C. A. M., Van Kan, J. A. L., and De Wit, P. J. G. M. 1993. Molecular characterization of four chitinase cDNAs obtained from Cladosporium fulvum-infected tomato. Plant Mol. Biol. 22:1017-1029.

De Wit, P. J. G. M. 1977. A light and scanning-electron microscopic study of infection of tomato plants by virulent and avirulent races of Cladosporium fulvum. Neth. J. Plant Pathol. 83:109-122.

De Wit, P. J. G. M. 1995. Fungal avirulence genes and plant resistance genes: Unraveling the molecular basis of gene-for-gene interactions. Adv. Bot. Res. 21:148-178.

De Wit, P. J. G. M., and Spikman, G. 1982. Evidence for the occurrence of race and cultivar-specific elicitors of necrosis in intercellular fluids of compatible interaction of Cladosporium fulvum and tomato. Physiol. Plant Pathol. 21:1-11.

Dellaporta, S. L., Chomet, P. S., Mottinger, J. P., Wood, J. A., Yu, S. M., and Hicks, J. B. 1984. Endogenous transposable element associated with virus infection in maize. Cold Spring Harbor Symp. Quant. Biol. 49:321-328.

Dixon, R. A., and Lamb, C. L. 1990. Molecular communication in interactions between plants and microbial pathogens. Annu. Rev. Plant Physiol. Plant Mol. Biol. 41:339-367.

Fedoroff, N. V. 1989. Maize transposable elements. Pages 375-411 in: Mobile DNA. D. E. Berg and M. M. Howe, eds. American Society for Microbiology, Washington.

Finnegan, D. J. 1992. Transposable elements. Curr. Opin. Genet. Dev. 2:861-867

Grandbastien, M.-A. 1998. Activation of plant retrotransposons under stress conditions. Trends Plant Sci. 3:181-187.

Grandbastien, M.-A., Lucas, H., Mhiri, C., Morel, J.-B., Vernhettes, S., and Casacuberta, J. M. 1997. The expression of the tobacco Tnt1 retrotransposon is linked to the plant defense responses. Genetica 100: 241-252.

Grandbastien, M.-A., Spielmann, A., and Caboche, M. 1989. Tnt1, a mobile retroviral-like transposable element of tobacco isolated by plant cell genetics. Nature 337:376-380.

Hammond-Kosack, K. E., Harrison, K., and Jones, J. D. G. 1994. Developmental regulated cell death on expression of the fungal avirulence gene $A v r 9$ in tomato seedlings carrying the disease-resistance gene $C f$ 9. Proc. Natl. Acad. Sci. USA 91:10445-10449.

Hammond-Kosack, K. E., and Jones, J. D. G. 1994. Incomplete dominance of tomato $C f$ genes for resistance to Cladosporium fulvum. Mol. Plant-Microbe Interact. 7:58-70.

Hammond-Kosack, K. E., and Jones, J. D. G. 1996. Resistance genedependent plant defense responses. Plant Cell 8:1773-1791.

Hammond-Kosack, K. E., and Jones, J. D. G. 1997. Plant disease resistance genes. Annu. Rev. Plant Physiol. Plant Mol. Biol. 48:575-607.

Hammond-Kosack, K. E., Silverman, P., Raskin, I., and Jones, J. D. G. 1996. Race-specific elicitors of Cladosporium fulvum induce changes in cell morphology and the synthesis of ethylene and salicylic acid in tomato plants carrying the corresponding $C f$ disease resistance gene. Plant Physiol. 110:1381-1394. 
Hirochika, H. 1993. Activation of tobacco retrotransposons during tissue culture. EMBO J. 12:2521-2528.

Hirochika, H. 1995. Regulation of plant retrotransposons and their use for genome analysis. Pages 77-89 in: Gamma Field Symposia no. 34. Institute of Radiation Breeding, NIAR, MAFF, Ohmiya-Machi, Japan.

Hirochika, H. 1997. Retrotransposons of rice: Their regulation and use for genome analysis. Plant Mol. Biol. 35:231-240.

Honée, G., Melchers, L. S., Vleeshouwers, V. G. A. A., van Roekel, J. S. C., and De Wit, P. J. G. M. 1995. Production of the AVR9 elicitor from the fungal pathogen Cladosporium fulvum in transgenic tobacco and tomato plants. Plant Mol. Biol. 29:909-920.

Jakobek, J. L., and Lindgren, P. B. 1993. Generalized induction of defense responses in bean is not correlated with the induction of the hypersensitive reaction. Plant Cell 5:49-56.

Jefferson, R. A., Kavanagh, T. A., and Bevan, M. W. 1987. GUS fusions: $\beta$-Glucuronidase as sensitive and versatile gene fusion marker in higher plants. EMBO J. 6:3901-3907.

Johns, M. A., Mottinger, J., and Freeling, M. 1985. A low copy number, copia-like transposon in maize. EMBO J. 4:1093-1102.

Joosten, M. H. A. J., Verbakel, H. M., Nettekoven, M. E., Van Leeuwen, J., Van der Vossen, R. T. M., and De Wit, P. J. G. M. 1995. The phytopathogenic fungus Cladosporium fulvum is not sensitive to the chitinase and $\beta-1,3$-glucanase defence proteins of its host, tomato. Physiol. Mol. Plant Pathol. 46:45-59.

Keen, N. T. 1990. Gene-for-gene complementarity in plant-pathogen interactions. Annu. Rev. Genet. 24:447-463.

Kessmann, H., Staub, T., Hofmann, C., Maetzke, T., Herzog, J., Ward, E., Uknes, S., and Ryals, J. 1994. Induction of systemic acquired disease resistance in plants by chemicals. Annu. Rev. Phytopathol. 32: 439-459.

Lamb, C., and Dixon, R. A. 1997. The oxydative burst in plant disease resistance. Annu. Rev. Plant Physiol. Plant Mol. Biol. 48:251-275.

Laterrot, H., and Clerjeau, M. 1979. Détermination des pathotypes de Fulvia fulva (= Cladosporium fulvum) présents sur tomate dans les serres françaises. Ann. Amélior. Plantes 29:447-462.

Logemann, J., Schell, J., and Willmitzer, L. 1987. Improved method for the isolation of RNA from plant tissues. Anal. Biochem. 163:16-20.

Lucas, H., Feuerbach, F., Kunert, K., Grandbastien, M.-A., and Caboche, M. 1995. RNA-mediated transposition of the tobacco retrotransposon Tnt1 in Arabidopsis thaliana. EMBO J. 14:2364-2373.

May, M. J., Hammond-Kosack, K. E., and Jones, J. D. G. 1996. Involvement of reactive oxygen species, glutathione metabolism, and lipid peroxidation in the $C f$-gene-dependent defense response of tomato cotyledons induced by race-specific elicitors of Cladosporium fulvum. Plant Physiol. 110:1367-1379.

McClintock, B. 1984. The significance of responses of the genome to challenge. Science 226:792-801.

Messiaen, C. M., and Lafon, R. 1970. Répertoire mycologique. Pages 387-419 in: Les maladies des plantes maraîchères. 2nd ed. Institut
National de la Recherche Agronomique, Paris.

Mhiri, C., Morel, J.-B., Vernhettes, S., Casacuberta, J. M., Lucas, H., and Grandbastien, M.-A. 1997. The promoter of the tobacco Tnt1 retrotransposon is induced by wounding and by abiotic stress. Plant Mol. Biol. 33:257-266.

Moreau-Mhiri, C., Morel, J.-B., Audéon, C., Ferault, M., Grandbastien, M.-A., and Lucas, H. 1996. Regulation of expression of the tobacco Tnt1 retrotransposon in heterologous species following pathogenrelated stresses. Plant J. 9:409-419.

Pellegrini, L., Rohfritsch, O., Fritig, B., and Legrand, M. 1994. Phenylalanine ammonia-lyase in tobacco. Plant Physiol. 106:877-886.

Pouteau, S., Grandbastien, M.-A., and Boccara, M. 1994. Microbial elicitors of plant defense responses activate transcription of a retrotransposon. Plant J. 5:535-542.

Pouteau, S., Huttner, E., Grandbastien, M.-A., and Caboche, M. 1991. Specific expression of the tobacco Tnt1 retrotransposon in protoplasts. EMBO J. 10:1911-1918.

Ryan, C. A., and Farmer, E. E. 1991. Oligosaccharide signals in plants: A current assessment. Annu. Rev. Plant Physiol. Plant Mol. Biol. 42: 651-674.

Strand, D. J., and McDonald, J. F. 1985. Copia is transcriptionally responsive to environmental stress. Nucleic Acids Res. 13:4401-4410.

Takeda, S., Sugimoto, K., Otsuki, H., and Hirochika, H. 1998. Transcriptional activation of the tobacco retrotransposon Tto1 by wounding and methyljasmonate. Plant Mol. Biol. 36:365-376.

Tigchelaar, E. C. 1984. Collections of isogenic tomato stocks. Rep. Tomato Genet. Coop. 34:55-57.

Tornero, P., Conejero, V., and Vera, P. 1994. A gene encoding a novel isoform of the PR-1 protein family from tomato is induced upon viroid infection. Mol. Gen. Genet. 234:47-53.

Tornero, P., Rodrigo, I., Conejero, V., and Vera, P. 1993. Nucleotide sequence of a cDNA encoding a pathogenesis-related protein, P1-p14, from tomato (Lycopersicon esculentum). Plant Physiol. 102:325.

Van Kan, J. A. L., Joosten, M. H. A. J., Wagemakers, C. A. M., Van den Berg-Velthuis, G. C. M., and De Wit, P. J. G. M. 1992. Differential accumulation of mRNAs encoding extracellular and intracellular PR proteins in tomato induced by virulent and avirulent races of $\mathrm{Cla}$ dosporium fulvum. Plant Mol. Biol. 20:513-527.

Vera-Estrella, R., Blumwald, E., and Higgins, V. J. 1992. Effect of specific elicitors of Cladosporium fulvum on tomato suspension cells. Plant Physiol. 99:1208-1215.

Vernhettes, S., Grandbastien, M.-A., and Casacuberta, J. M. 1997. In vivo characterization of transcriptional regulatory sequences involved in the defence associated expression of the tobacco retrotransposon Tnt1. Plant Mol. Biol. 35:673-679.

Wubben, J. P., Lawrence, C. B., and De Wit, P. J. G. M. 1996. Differential induction of chitinase and 1,3- $\beta$-glucanase gene expression in tomato by Cladosporium fulvum and its race-specific elicitors. Physiol. Mol. Plant Pathol. 48:105-116. 